
\title{
Year-End Clinic Handoffs: A National Survey of Academic
Internal Medicine Programs
}

\author{
Erica Phillips, MD, $\mathrm{MS}^{7}$, Christina Harris, $\mathrm{MD}^{2}$, Wei Wei Lee, MD MPH${ }^{3}$, Amber T. Pincavage, $\mathrm{MD}^{3}$, \\ Karin Ouchida, $M D^{4}$, Rachel K. Miller, $M D^{5}$, Saima Chaudhry, MD', and Vineet M. Arora, $M D^{3}$
}

\begin{abstract}
'Division of General Internal Medicine, Weill Cornell Medicine, New York, NY, USA; ${ }^{2}$ Department of Medicine, VA Greater Los Angeles Healthcare System, David Geffen School of Medicine at UCLA, Los Angeles, CA, USA; ${ }^{3}$ Department of Medicine, University of Chicago Medical Center, Chicago, IL, USA; 'Division of Geriatrics and Palliative Medicine, Weill Cornell Medicine, New York, NY, USA; ${ }^{5}$ Division of Geriatric Medicine, Department of Medicine, University of Pennsylvania, Philadelphia, PA, USA; ${ }^{6}$ Department of Medicine, Memorial Healthcare System, Hollywood, FL, USA
\end{abstract}

BACKGROUND: While there has been increasing emphasis and innovation nationwide in training residents in inpatient handoffs, very little is known about the practice and preparation for year-end clinic handoffs of residency outpatient continuity practices. Thus, the latter remains an identified, yet nationally unaddressed, patient safety concern.

OBJECTIVES: The 2014 annual Association of Program Directors in Internal Medicine (APDIM) survey included seven items for assessing the current year-end clinic handoff practices of internal medicine residency programs throughout the country.

DESIGN: Nationwide survey.

PARTICIPANTS: All internal medicine program directors registered with APDIM.

MAIN MEASURES: Descriptive statistics of programs and tools used to formulate a year-end handoff in the ambulatory setting, methods for evaluating the process, patient safety and quality measures incorporated within the process, and barriers to conducting year-end handoffs.

KEY RESULTS: Of the 361 APDIM member programs, 214 (59\%) completed the Transitions of Care Year-End Clinic Handoffs section of the survey. Only 34\% of respondent programs reported having a year-end ambulatory handoff system, and 4\% reported assessing residents for competency in this area. The top three barriers to developing a year-end handoff system were insufficient overlap between graduating and incoming residents, inability to schedule patients with new residents in advance, and time constraints for residents, attendings, and support staff.

CONCLUSIONS: Most internal medicine programs do not have a year-end clinic handoff system in place. Greater attention to clinic handoffs and resident assessment of this care transition is needed.

KEY WORDS: patient safety; transfer of care; handoff; sign-out; continuity of care.

Received September 30, 2016

Revised December 30, 2016

Accepted January 25, 2017

Published online February 14, 2017
J Gen Intern Med 32(6):667-72

DOI: $10.1007 / \mathrm{s} 11606-017-4005-2$

(c) Society of General Internal Medicine 2017

\section{INTRODUCTION}

As advised by the Joint Commission, all health care organizations should have a standardized approach to handoff communication that includes the opportunity for providers to ask and respond to questions. ${ }^{1}$ While the frequency of handoffs may be greater in the hospital, the concerns regarding patient safety are equally relevant to transitions that occur in academic ambulatory practices each year when residents advance to a higher level of training or graduate. These "year-end transfers" affect approximately 1.9 million patients in resident ambulatory care practices annually. ${ }^{2}$ To date, several aspects of the year-end handoff process have been studied, including 1) the handoff structure, 2) patient safety and outcomes, and 3) the subjective experiences of patients and graduate medical trainees. $^{3-9}$

In 2012, Donnelly et al. conducted a survey of medicinepediatric program directors to examine the year-end transition process. They found that fewer than half of the responder programs (31/67) had an outpatient handoff system, and the characteristics of those systems were highly variable. ${ }^{10}$ In evaluating the scope of what should be included in a handoff, one study revealed that $87 \%$ of residents wanted written handoffs for patients with complex medical or social issues, while only $35 \%$ felt it would be useful for patients with no significant issues. ${ }^{11}$ Handoffs with a structure similar to inpatient handoffs, including a brief summary of active medical conditions and a clinical task list, have been suggested as the most useful format. ${ }^{12}$

Several studies have demonstrated higher rates of missed appointments, discontinuity with newly assigned physicians, loss to follow-up care, and lack of follow-up on outstanding clinical tests in the post-handoff period. In one study, only $43 \%$ of high-priority patients returned for follow-up care 
within a year of their former residents' graduation. ${ }^{6}$ Similarly, at another medical center, despite $97 \%$ of high-risk patients having a scheduled appointment with their newly assigned provider, $42 \%$ did not follow up within a year. Furthermore, 6 months post-graduation, 54\% of signed-out tests (of which $65 \%$ were abnormal or incomplete) were not followed up. ${ }^{3}$ Several academic centers have described interventions that have improved the handoff process and outcomes. ${ }^{12-15}$ In a prospective study among psychiatric patients, the identification of high-risk patients, who were given longer appointments during the first month after the transfer and were contacted by a clinician, led to fewer hospitalizations. ${ }^{16}$ Additionally, a 24-month multifaceted handoff intervention targeting high-risk primary care patients reduced the number of acute visits to the emergency room or hospital in the 3month post-handoff period. ${ }^{4}$

Patients report facing challenges in establishing new patient-physician relationships after residency clinic handoffs, and experience lapses in their care. ${ }^{5}$ Similarly, resident physicians have noted that inadequate information on their new patients led to additional work (80\%), delayed needed care $(56 \%)$, and disrupted continuity $(58 \%) .{ }^{11} \mathrm{Un}$ fortunately, almost $50 \%$ of residents do not feel personally responsible for their assigned patients until they have seen them in practice. ${ }^{3}$

The documented safety concerns that have evolved from the lack of a structured ambulatory care handoff process suggest a critical need to improve this process in internal medicine programs. Given that there is no national benchmark describing the prevalence of these educational activities, we aim to describe the current state of affairs in this area of residency training.

\section{METHODS}

In 2012, a pilot cross-sectional survey of all accredited internal medicine residency programs in the United States was conducted as part of a larger year-end clinic handoff project at Weill Cornell Medicine. Three hundred seventy-one eligible programs were identified by searching the Fellowship and Residency Electronic Interactive Database Access (FREIDA) system. The pilot survey was emailed to program directors, with instructions to redirect the survey to an ambulatory care site director if they felt that person was better suited to complete the survey. The survey comprised 20 multiple choice questions which inquired about the mechanism of handoff (oral or written), the format of written handoff (standard form or individually created by each resident), and whether programs provided handoff training. The pilot data revealed that $32 \%(n=34)$ of respondent programs (31\% response rate) had an end-of-year sign-out process, with only $19 \%$ of those programs actually providing training on how to prepare the sign-out. The top two responses regarding barriers to having a handoff process were 1) too time-intensive for the residents and 2) never having thought about it.
Using this information, eight key questions on year-end clinic handoffs were incorporated into the 2014 APDIM survey, which is an annual survey of U.S. internal medicine residency program directors. ${ }^{17}$ The majority of questions not included from the pilot survey were on program demographics already captured by the APDIM survey. The 2014 survey queried program directors on the parent topic of transitions of care in four settings (inpatient, discharge management, home health care, and year-end clinic handoff). Core sections of the APDIM survey can be found at http://www.im.org/p/cm/ld/fid=506). The survey was administered by the Mayo Clinic Survey Research Center between August and November of 2014 to all program directors.

\section{DATA ANALYSIS}

Descriptive statistics were used to summarize responder programs to the APDIM survey. Statistical significance of group differences was tested using the Wilcoxon test for continuous variables and Pearson $\mathrm{x}^{2}$ or Fishers exact tests for categorical variables, where appropriate. Programs were defined as having a year-end clinic handoff process if they reported systematically doing any of the following:

1) Storing an electronic/written sign-out document in the patient's outpatient chart

2) Using an electronic/written sign-out document for a faceto-face sign-out

3) Giving an electronic/written sign-out document to the accepting outpatient provider

Logistic regression models were used to evaluate programmatic variables of interest, determined by an extensive literature search, that would be associated with having a year-end clinic handoff. The hypothesized variables of interests were usage of an EHR, the presence of formal didactic sessions on handoffs as they relate to transitions across all aspects of the health care system, mechanisms for measuring patient safety after the year-end transition, the presence of a primary care track, program size, programmatic support as measured by core faculty, and whether the program director was a general internist. We used SPSS statistical software (SPSS Advanced Statistics version 23.1; IBM Corp., Armonk, NY) for all statistical analyses and a $p$ value of 0.05 as significant. The pilot study was approved by the Weill Cornell Medical College and the overall study by the Mayo Clinic Institutional Review Board.

\section{RESULTS Program Characteristics}

Of the 361 internal medicine residency program directors surveyed, 234 responded to the overall survey $(64.8 \%$ 
response rate), and 214 completed the Transitions of Care Year-End Clinic Handoffs section of the survey. Community-based university-affiliated hospital programs (60\% non-response rate) and smaller programs (median number of ACGME positions, 51) were less likely to respond. University-based programs (40\% response rate) and programs with primary care tracks ( $26 \%$ response rate) were more likely to respond, as shown in Table 1.

\section{Handoff Characteristics}

Year-End Clinic Handoff Process. Among respondents, 34\% of program directors $(n=71)$ reported having a year-end clinic handoff process. While the components of the sign-out varied among programs, the majority $(53 / 71)$ had an electronic or written sign-out that was placed in the chart. Fewer programs (20/71) conducted a face-to-face sign-out. Thirty-nine percent of programs reported that graduating residents were expected to update the problem list for their clinic patients. However, this response did not meet our criteria for a year-end sign-out. Thirty-eight percent of programs reported that graduating residents were not expected to prepare a sign-out. Almost half ( $n=101)$ of program directors reported working on improving their year-end clinic handoff process.

Most programs (95\%) had a standardized system for patient end-of-year reassignments. The majority $(61 \%)$ reassigned continuity panels to incoming interns (either in a block or divided among several trainees; Table 2), while few (13\%) programs took into account patient factors when reassigning patients. Among those that did, the patients risk level was the most commonly cited reason for reassigning to an upper-level resident or attending physician.

Programs reported several barriers to implementing a yearend clinic handoff process. The most frequent were lack of an overlap between outgoing and incoming residents (42\%) and the inability to schedule appointments with new residents in advance (34\%). The third most common barrier was the time required by residents (32\%), attendings (25\%) and/or support staff $(23 \%)$ to support a handoff process.

Although there were several variables that we hypothesized would have a significant impact on programs having an endof-year handoff, they were ultimately excluded because they did not improve the statistical fit of the model. As shown in Table 3, residency programs were more than twice as likely to have a year-end handoff process if they already had an EHRbased inpatient handoff system in place (adjusted OR 2.27; $95 \%$ CI 1.13, 4.57; $p=0.021)$.

Year-End Clinic Handoff Education and Assessment. Thirtyeight percent of programs reported that their residents were not receiving any components of year-end clinic handoff education (as listed in Table 2, "Handoff Education"). In comparison, far fewer programs lacked any formal education on discharge management $(8 \%)$ or inpatient handoff education (4\%). The most common mechanism $(51 \%)$ for patient safety monitoring after the year-end handoff was the identification and enhanced follow-up of high-risk patients.

Table 1 Characteristics of Internal Medicine Residency Programs from the APDIM 2014 Survey $(N=361)$

\begin{tabular}{|c|c|c|c|}
\hline Characteristic & Non-responder $(n=147)$ & Responder $(n=214)$ & $p$ value \\
\hline \multicolumn{4}{|l|}{ Program description, $n(\%)$} \\
\hline Community-based, university-affiliated hospital & $88(59.9)$ & $105(49.1)$ & \multirow[t]{4}{*}{$0.021^{*}$} \\
\hline University-based & $41(27.9)$ & $85(39.7)$ & \\
\hline Community-based & $12(8.2)$ & $22(10.3)$ & \\
\hline Military & $6(4.1)$ & $2(0.9)$ & \\
\hline \multicolumn{4}{|l|}{ Census region, $n(\%)$} \\
\hline Northeast & $50(39.7)$ & $76(60.3)$ & \multirow[t]{5}{*}{0.947} \\
\hline South & $42(44.2)$ & $53(55.8)$ & \\
\hline Midwest & $34(40.0)$ & $51(60.6)$ & \\
\hline West & $20(38.5)$ & $32(61.5)$ & \\
\hline Unincorporated territory & $1(33.3)$ & $2(66.7)$ & \\
\hline \multicolumn{4}{|l|}{ Government affiliation, $n(\%)$} \\
\hline No & $140(95.2)$ & $205(95.8)$ & \multirow{2}{*}{0.8} \\
\hline Yes & $7(4.8)$ & $9(4.2)$ & \\
\hline \multicolumn{4}{|l|}{ Program director years of tenure } \\
\hline Median (25th to 75 th percentile) & $3(1-8)$ & $5(2-9.25)$ & \multirow[t]{2}{*}{0.159} \\
\hline Range & $0-32$ & $0-33$ & \\
\hline Program has a primary care track, $n \%$ & $6(4)$ & $56(26)$ & $<0.001 *$ \\
\hline \multicolumn{4}{|l|}{ ACGME-approved positions } \\
\hline Median (25th to 75 th percentile) & $51(36-79)$ & $64.5(39.7-99)$ & \multirow{2}{*}{$0.015^{*}$} \\
\hline Range & $21-181$ & $15-179$ & \\
\hline \multicolumn{4}{|l|}{ ABIM program pass rate $(2011-2013)^{\dagger}$} \\
\hline Median (25th to 75 th percentile) & $86(21-181)$ & $87(15-179)$ & \multirow{2}{*}{0.209} \\
\hline Range & $79-91$ & $81-92$ & \\
\hline \multicolumn{4}{|l|}{ FREIDA year 1 positions } \\
\hline Median (25th to 75 th percentile) & $17(12-27)$ & $23(13.5-36.5)$ & \multirow{2}{*}{$0.011 *$} \\
\hline Range & $8-64$ & $8-72$ & \\
\hline \multicolumn{4}{|l|}{ No. of participating institutions, $n(\%)$} \\
\hline$\leq 2$ & $94(63.9)$ & $123(57.5)$ & \multirow[t]{2}{*}{0.217} \\
\hline$>2$ & $53(58.6)$ & $91(42.5)$ & \\
\hline
\end{tabular}

ABIM American Board of Internal Medicine

${ }^{*} p$ value $<0.05^{\dagger} N=351^{\ddagger} N=296$ 
Table 2 Handoff characteristics $(N=\mathbf{2 1 0})$

\begin{tabular}{|c|c|}
\hline Topic area & $\begin{array}{l}\text { No. } \\
(\%)\end{array}$ \\
\hline \multicolumn{2}{|l|}{ Handoff process (panel reassignment) } \\
\hline To incoming intern & $83(39)$ \\
\hline Divided among interns and residents & $73(34)$ \\
\hline Divided among $>1$ intern & $49(23)$ \\
\hline Patient factor-dependent & $29(14)$ \\
\hline To PGY-2 or PGY-3 & $18(8)$ \\
\hline To an attending & $15(7)$ \\
\hline No standard reassignment & $11(5)$ \\
\hline Other & $7(3)$ \\
\hline Don't know & $4(2)$ \\
\hline \multicolumn{2}{|l|}{ Format of written information transfer (sign-out) } \\
\hline Update chart problem list & $82(39)$ \\
\hline Not expected to prepare a sign-out & $79(38)$ \\
\hline $\begin{array}{l}\text { Electronic or written sign-out document placed in patient's } \\
\text { chart }\end{array}$ & $53(25)$ \\
\hline $\begin{array}{l}\text { Electronic or written sign-out document signed face-to- } \\
\text { face }\end{array}$ & $20(10)$ \\
\hline $\begin{array}{l}\text { Electronic or written sign-out document given to } \\
\text { accepting provider }\end{array}$ & $19(9)$ \\
\hline Don't know & $13(6)$ \\
\hline \multicolumn{2}{|l|}{ Handoff education } \\
\hline Educate residents on how to conduct end-of-ye & $67(31)$ \\
\hline Re-balance caseload to distribute complex patients equally & $35(16)$ \\
\hline $\begin{array}{l}\text { Faculty supervision or involvement in clinic handoff } \\
\text { process }\end{array}$ & $34(16)$ \\
\hline Provide standardized template for written sign-out & $33(15)$ \\
\hline $\begin{array}{l}\text { Provide protected time for handoff activities (i.e., } \\
\text { preparation, face-to-face handoff) }\end{array}$ & $32(15)$ \\
\hline $\begin{array}{l}\text { Introduce incoming resident PCP in person during visit } \\
\text { with outgoing resident }\end{array}$ & $18(8)$ \\
\hline Assess competency of residents in handoff process & $9(4)$ \\
\hline None of the above & $82(35)$ \\
\hline Don’t know & $18(8)$ \\
\hline \multicolumn{2}{|l|}{ Patient care processes } \\
\hline Communicate to patients about pending transition & $98(46)$ \\
\hline $\begin{array}{l}\text { Identify high-risk patients at risk for poor handoff } \\
\text { outcomes }\end{array}$ & $48(22)$ \\
\hline Provide enhanced handoff for high-risk patients & $38(18)$ \\
\hline Schedule high-risk patients with a designated provider & $23(11)$ \\
\hline Monitor patients lost to follow-up after year-end handoff & $16(8)$ \\
\hline Monitor time to first appointment for handoff patients & $14(7)$ \\
\hline $\begin{array}{l}\text { Provide patients with additional outreach at transition } \\
\text { point }\end{array}$ & $14(7)$ \\
\hline None of the above & $57(24)$ \\
\hline Don’t know & $23(10)$ \\
\hline \multicolumn{2}{|l|}{ Barriers to year-end handoff process } \\
\hline $\begin{array}{l}\text { Not enough overlap between outgoing and incoming } \\
\text { residents }\end{array}$ & $87(41)$ \\
\hline $\begin{array}{l}\text { Unable to schedule patients with new interns until their } \\
\text { schedule is available }\end{array}$ & $71(34)$ \\
\hline Too time-intensive for house staff & $67(32)$ \\
\hline Too time-intensive for supervising attending physicians & $54(25)$ \\
\hline Too time-intensive for support staff & $49(23)$ \\
\hline Lack of patient continuity in resident clinic & $49(23)$ \\
\hline Residents don't feel sense of ownership of clinic patients & $41(20)$ \\
\hline $\begin{array}{l}\text { Unable to identify a resident as the primary care provider } \\
\text { in patient record }\end{array}$ & $39(18)$ \\
\hline Program culture does not deem it necessary & $26(13)$ \\
\hline $\begin{array}{l}\text { Unable to perform high-priority scheduling for high-risk } \\
\text { patients }\end{array}$ & $23(11)$ \\
\hline No barriers & $22(10)$ \\
\hline Unable to identify high-risk patients & $13(6)$ \\
\hline Other/don't know & $28(13)$ \\
\hline
\end{tabular}

PGY postgraduate year

Only $10(5 \%)$ programs reported assessing resident competency when performing end-of-year clinic handoffs (Table 2). A minority of program directors (21\%) strongly or somewhat agreed that year-end clinic handoffs were adequately addressed by their programs. Data from the larger APDIM survey revealed that in response to the question, "Which of the following of the 22 ACGME sub-competencies are EASIEST for you to objectively assess?", only $3 \%$ of program directors selected safe transitions of care within/across health delivery systems.

\section{DISCUSSION}

In this study, we assessed the current state of year-end handoffs in internal medicine residency programs and described the characteristics of programs that had succeeded in putting a process in place. To the best of our knowledge, this is the first study to systematically evaluate outpatient transitions of care among internal medicine residency programs nationally. Despite increased recognition of the risks inherent in these handoffs, we found that only about one-third of the programs had a year-end clinic handoff process. The top three barriers to developing such a system were a lack of overlap between outgoing and incoming residents, inability to schedule patients with new residents in advance, and perceived time intensity for residents, attendings, and support staff. The identification of these barriers offers an opportunity to address these challenges and develop a systems-based approach to improve year-end clinic handoffs.

In 2011, the Accreditation Council for Graduate Medical Education (ACGME) released its resident duty hours restrictions requiring that faculty monitor their residents' patient handoffs to ensure resident competency in handoff communications. Our survey results highlight significant gaps in the adoption of these guidelines in the ambulatory care setting. In order to address this issue on a national level, ACGME should consider expanding its program requirements on transitions in the health care system to explicitly include language on yearend clinic handoffs. ${ }^{18}$ To our knowledge, the 2014 APDIM survey was the first national survey to query about handoff communication in all four aspects of health care transitions, including the ambulatory setting.

Using best practices from existing year-end clinic handoff interventions, the following approach should be considered for improving this transition. First, identifying patients at high risk for suboptimal outcomes should be a goal of all health care delivery systems. Hospitals that have adopted accountable care organization or patient-centered medical home models with electronic health records have the capacity to identify high-risk patients based on comorbidities and health care utilization. In health care systems that do not utilize EHRs, electronic scheduling systems could identify patients with high no-show rates. Residents themselves could likely identify within their own practices the most challenging patients. Subsequently ensuring that these high-risk patients have enhanced oversight and prioritized scheduling with either their new provider or a designated intermediary (i.e., a nurse practitioner, covering resident, attending) is critical to ensuring a safe transfer of care. High-risk patients with a significant no-show rate should be tracked, and missed appointments rescheduled, ideally with social work or 
Table 3 Odds of Having a Year-End Handoff Process $(N=210)$

\begin{tabular}{|c|c|c|c|}
\hline \multirow[t]{2}{*}{ Program characteristics } & \multicolumn{2}{|c|}{ Odds ratio $(95 \% \mathrm{CI})$} & \multirow[t]{2}{*}{$p$ value } \\
\hline & Unadjusted & Adjusted* & \\
\hline \multicolumn{4}{|l|}{ Program type } \\
\hline Community-based, university-affiliated & 1.0 (reference) & 1.0 (reference) & \\
\hline Community-based & $1.27(0.47-3.43)$ & $1.15(0.40-3.33)$ & 0.79 \\
\hline University-based & $2.03(1.10-3.75)$ & $1.53(0.61-3.85)$ & 0.37 \\
\hline \multicolumn{4}{|l|}{ Census region } \\
\hline Midwest & 1.0 (reference) & 1.0 (reference) & \\
\hline Northeast & $1.07(0.50-2.79)$ & $1.08(0.48-2.42)$ & 0.85 \\
\hline South & $1.32(0.59-2.98)$ & $1.34(0.57-3.18)$ & 0.50 \\
\hline West & $1.09(0.42-2.86)$ & $1.31(0.41-3.11)$ & 0.81 \\
\hline Presence of a primary care track & $2.10(1.12-3.94)$ & $1.45(0.69-3.03)$ & 0.33 \\
\hline \multicolumn{4}{|l|}{ Size of program by ACGME-approved positions } \\
\hline$<24$ (small) & 1.0 (reference) & 1.0 (reference) & \\
\hline 24-80 (medium) & $1.23(0.25-6.71)$ & $0.96(0.14-6.47)$ & 0.97 \\
\hline$>80$ (large) & $2.07(0.39-10.92)$ & $1.05(0.44-2.55)$ & 0.91 \\
\hline EMR used to create a sign-out for inpatient handoff & $2.56(1.34-5.03)$ & $2.28(1.13-4.57)$ & 0.02 \\
\hline Programs that do some form of patient safety monitoring after the year-end clinic handoff & $1.02(0.25-4.22)$ & $0.79(0.18-3.53)$ & 0.77 \\
\hline Programs with didactic education on inpatient handoffs or hospital discharge management & $1.44(0.77-2.71)$ & $1.44(0.74-2.88)$ & 0.28 \\
\hline
\end{tabular}

ACGME Accreditation Council for Graduate Medical Education, EMR electronic medical record

*Adjusted for program characteristics

care management involvement to address barriers (e.g., transportation). Furthermore, allotting additional time for the new resident provider to either contact the patient prior to the visit or conduct an extended first visit to specifically address items in the sign-out from the sending provider would be valuable. A previsit introductory phone call to high-risk patients would help patients feel more connected to their new providers and would encourage residents to assume ownership of their patients prior to the first visit. ${ }^{55}$ Recent studies ${ }^{19}$ demonstrate that a higher likelihood of no-show outpatient visits is a strong independent predictor of lower preventive cancer screening and chronic disease control rates at 1-year follow-up and higher rates of ED visits and hospitalizations in the subsequent 3 years. Implementing the strategies discussed above may help to reduce no-show rates and associated poor outcomes for high-risk patients during this critical period.

Addressing the needs of high-risk patients during this vulnerable time represents a valuable opportunity to improve patient care and to evaluate residents' handoff practices. Ideally, in systems where residents have clear continuity panels, the identification of high-priority patients by the graduating resident physician is equally important. Programs could evaluate and provide feedback on a resident's ability to accurately assess patient risk and priority, in addition to his or her ability to create a comprehensive and meaningful sign-out. In work conducted at a moderate-sized urban residency program, ${ }^{12}$ we learned that the average continuity panel among graduating residents was 98 patients (range 57160). More importantly, residents identified on average 41 continuity patients and only nine high-priority patients per sign-out. Comparable studies have shown a similar average number of high-priority patients per resident. ${ }^{3}$ Thus, the year-end clinic handoff should focus on the identification of this relatively small annual number of patients per resident to ensure that care for this group is enhanced during the transition to a new provider.

Second, it is well recognized that handoffs are more than the passive transfer of information. The cornerstone of the handoff is a bidirectional conversation with active involvement of the sender and the receiver. ${ }^{20}$ Whenever possible, the year-end clinic handoff should be designed to include a face-to-face transfer of information and responsibility of duties for a designated group of patients. For some programs, this activity could take place during intern orientation week, whereas in those where there is no overlap, the reassignment to a rising second- or third-year resident affords the opportunity for a face-to-face handoff. Our results revealed that the most common mechanism $(75 \%)$ of ambulatory handoffs among programs with a process in place was an electronic or written sign-out document that was either placed in the EHR chart or given to the next provider of care directly. Having an EHRbased handoff may serve as a proxy for a program that has a focus on improving care transitions overall. Hence, residency programs with an EHR-based inpatient handoff system in place were more than twice as likely to have a year-end handoff process in place as well. These programs should serve as models for overcoming the barrier of no-overlap between incoming and outgoing residents.

Lastly, programs should include year-end clinic handoff education as part of their required curriculum for residents. Over $90 \%$ of program directors responded that they already had skill-building didactics for handoff communication in discharge management and inpatient handoffs. Thus, the addition of the ambulatory care transition should not present a substantial burden. Presently, published curricula and teaching videos are available for educators in internal medicine to provide clinic handoff education. ${ }^{21}$

Our study is limited in a few respects. For example, it represents only those program directors who are members of APDIM and who responded to the transfer of care section, which may introduce selection bias. However, we believe this bias to be toward programs that have a process in place. Community-based programs and smaller programs that were less likely to respond to the APDIM survey are also less likely to have a year-end sign-out process in place. 
In addition, the sample size may not be sufficiently robust to detect other key distinguishing factors of programs with an established handoff process. Furthermore, program directors may not have the most up-to-date information regarding ambulatory education and ambulatory handoffs within their programs, which could also have affected our results. Lastly, we did not explore patient outcomes. Given the small number of single-institution interventions in this area, a robust effect on patient outcomes remains to be seen. Additional research is needed to better understand how to effectively improve the year-end clinic handoff process across programs, examining both clinical and patient-centered outcomes.

Our study demonstrates that there is still much work to be done in programs assessing and developing clear strategies to address an important competency. Clear distinctions must be made between best practices for inpatient and outpatient handoffs in order to reduce perceived barriers. There are several low-cost methods that have been implemented in this area that could be implemented in comparable programs with and without an EHR system across all outpatient disciplines.

In summary, despite being a known safety risk for ambulatory patients in resident clinics, year-end clinic handoffs remain largely unaddressed in the majority of internal medicine residency programs. In a health care environment with an increasing emphasis on population health management and improving the value of healthcare, rigorous formal efforts toward improving year-end clinic handoffs in internal medicine residency programs are warranted.

Acknowledgements: The authors wish to thank the entire APDIM Survey and Scholarship Committee, as well as Andrew Halvorsen, Libby Hammond, and the Mayo Clinic Survey Research Center for their assistance in administering the survey.

Corresponding Author: Erica Phillips, MD, MS; Division of General Internal MedicineWeill Cornell Medicine, New York, NY, USA (e-mail:erp2001@med.cornell.edu).

\section{Compliance with Ethical Standards:}

Conflict of Interest: The authors declare that they do not have a conflict of interest.

\section{REFERENCES}

1. The Joint Commission. Facts about the Hand-off Communications Project. August 1, 2009. Accessed February 9, 2017. http://www. centerfortransforminghealthcare.org/assets/4/6/CTH_HOC_Fact_Sheet.pdf.

2. Young JQ, Wachter RM. Academic year-end transfers of outpatients from outgoing to incoming residents: an unaddressed patient safety issue. JAMA. 2009;302(12):1327-9.
3. Pincavage AT, Ratner S, Prochaska ML, Prochaska M, Oyler J, Davis AM, et al. Outcomes for resident-identified high-risk patients and resident perspectives of year-end continuity clinic handoffs. J Gen Intern Med. 2012.

4. Pincavage AT, Prochaska M, Dahlstrom M, Lee WW, Beiting KJ, Ratner S, et al. Patient safety outcomes after two years of an enhanced internal medicine residency clinic handoff. Am J Med. 2014;127(1):96-9.

5. Pincavage AT, Lee WW, Beiting KJ, Arora VM. What do patients think about year-end resident continuity clinic handoffs? A qualitative study. J Gen Intern Med. 2013;28(8):999-1007.

6. Caines LC, Brockmeyer DM, Tess AV, Kim H, Kriegel G, Bates CK. The revolving door of resident continuity practice: identifying gaps in transitions of care. J Gen Intern Med. 2011;26(9):995-8.

7. Bates CK, Caines LC, Brockmeyer D, Kim H, Tess A, Kriegel G. Transfer of graduating residents' continuity practices. J Gen Intern Med. 2011.

8. Young JQ, Eisendrath SJ. Enhancing patient safety and resident education during the academic year-end transfer of outpatients: lessons from the suicide of a psychiatric patient. Acad Psychiatry. 2011;35(1):54-

9. Roy MJ, Herbers JE, Seidman A, Kroenke K. Improving patient satisfaction with the transfer of care. A randomized controlled trial. J Gen Intern Med. 2003; 18(5):364-9.

10. Donnelly MJ, Clauser JM, Tractenberg RE. Current practice in end-ofresidency handoffs: a survey of internal medicine-pediatrics program directors. J Grad Med Educ. 2013;5(1):93-7.

11. Lerner CF, Hamilton LJ, Klitzner TS. Improving year-end transfers of care in academic ambulatory clinics: a survey of pediatric resident physician perceptions. Med Educ Online. 2012;17. doi:10.3402/meo. v17i0.17815.

12. Garment AR, Lee WW, Harris C, Phillips-Caesar E. Development of a structured year-end sign-out program in an outpatient continuity practice. J Gen Intern Med. 2013;28(1):114-20.

13. Pincavage AT, Lee WW, Venable LR, Prochaska M, Staisiunas DD, Beiting $\mathbf{K J}$, et al. "Ms. B changes doctors": using a comic and patient transition packet to engineer patient-oriented clinic handoffs (EPOCH). J Gen Intern Med. 2015;30(2):257-60.

14. Donnelly MJ, Clauser JM, Tractenberg RE. A multicenter intervention to improve ambulatory care handoffs at the end of residency. J Grad Med Educ. 2014;6(1):112-6.

15. Donnelly MJ, Clauser JM, Weissman NJ. An intervention to improve ambulatory care handoffs at the end of residency. J Grad Med Educ. 2012;4(3):381-4.

16. Young JQ, Pringle Z, Wachter RM. Improving follow-up of high-risk psychiatry outpatients at resident year-end transfer. Jt Comm J Qual Patient Saf. 2011;37(7):300-8.

17. Alliance for Academic IM. 2014 APDIM survey data. 2015.

18. Riebschleger M, Philibert I. New standards for transitions of care: discussion and justification. In: Philibert I, Amis SJ, eds. The ACGME 2011 Duty Hour Standards: Enhancing Quality of Care, Supervision, and Resident Professional Development, Chicago, IL, Accreditation Council for Graduate Medical Education (ACGME); 2011:57.

19. Hwang AS, Atlas SJ, Cronin P, Ashburner JM, Shah SJ, He W, et al. Appointment "no-shows" are an independent predictor of subsequent quality of care and resource utilization outcomes. J Gen Intern Med. 2015;30(10): 1426-33.

20. Cheung DS, Kelly JJ, Beach C, Berkeley RP, Bitterman RA, Broida RI, et al. Improving handoffs in the emergency department. Ann Emerg Med. 2010;55(2): 171-80.

21. Pincavage AT, Lee W, Ratner S. Teaching video and checklist: "falling through the cracks: year end resident clinic handoffs”. 2012;2016(December 23). 